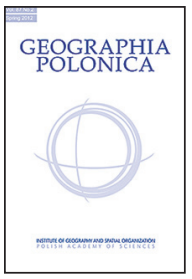

\title{
WHAT DETERMINES FOREST LITTER DECOMPOSITION? GLOBAL TRENDS AND LOCAL VARIANCE
}

\section{Ryszard Laskowski}

\author{
Jagiellonian University \\ Institute of Environmental Sciences \\ Gronostajowa 7, 30-387 Kraków: Poland \\ e-mail address: ryszard.laskowski@uj.edu.pl
}

\begin{abstract}
Global patterns in forest leaf litter decomposition has been studied for decades. The result has been the formulation of a range of models relating organic matter decay rate to climatic and litter-specific factors. It is now commonly accepted that the prime factor determining the litter decomposition rate on a global scale, is actual evapotranspiration (AET). However, this main effect can be seriously modified by the chemical composition of organic matter itself, resulting in large variance at local scales. Among leaf litter components, the lignin concentration, content of water-soluble compounds, concentration of nitrogen and some other nutrients have been indicated by different authors as the major determinants of litter decomposition rate. Unfortunately, our understanding of the factors regulating the decomposition is still far from satisfactory as indicated by the failure of existing models to predict properly litter decay rate in many cases. These include especially ecosystems from outside the temperate climate, such as boreal and wet tropical forests. The existing models still cannot explain the large differences in litter decomposition rates between species, even within reasonably wellstudied temperate forests. My article presents several reasons for the problem of finding satisfactory litter decomposition models. The most important reason is the bias in studies towards temperate ecosystems, high inter-correlations between chemical characteristics of litter and soil, and the lack of properly designed studies on very broad geographic scales.
\end{abstract}

\section{Key words}

chemistry $\bullet$ climate $\bullet$ decay $\bullet$ models $\bullet$ organic matter $\bullet$ soil $\bullet$ turnover

\section{The early models}

One of the most important and interesting goals of ecology is describing patterns observed in ecosystems with mathematical models, which allow to summarize and understand the underlining processes and relationships. Such global patterns as relationships between climate and ecosystem productivity or biodiversity have already been recognized by great 19 th century scientists and travelers like Alexander von Humboldt and Charles Darwin. The observations had to wait until the development of modern science to be fully appreciated and at least partly understood. Indeed, "partly" is the key word as some of the observed latitudinal patterns are still the subject of major controversies among scientists. One of the most important and interesting goals of ecology is describing patterns observed in ecosystems with mathematical models, which allow to summarize and understand the underlining processes and relationships.

In terms of our understanding the patterns, organic matter decomposition rate can be placed 

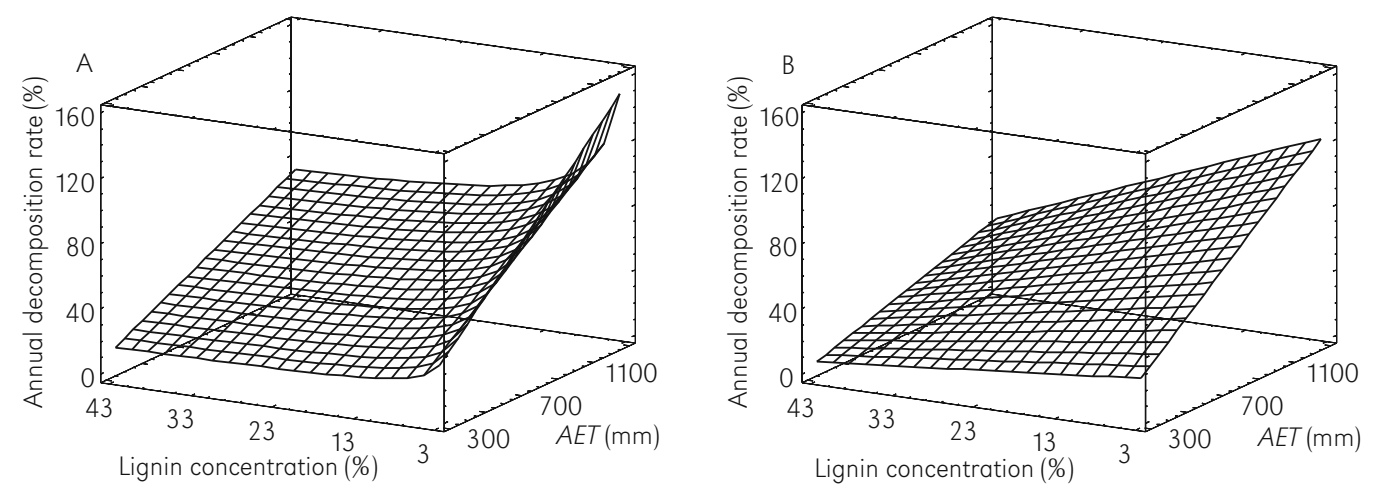

Figure 1. Three-dimensional representations of the two decomposition models relating the decomposition rate (\% decomposed in a year) to the lignin concentration in litter and actual evapotranspiration (AET).

Source: A - model by Meetnemeyer (1978), B - model by Meentemeyer (1984).

somewhere in between the productivity pattern (basically, fully explained) and biodiversity pattern (still poorly understood). Years ago, it was already recognized that the forest leaf litter decomposition rate changes dramatically across large geographic gradients (e.g., Meentemeyer 1978, 1984). It seemed obvious that some climatic factors must be the main driving forces of the decay. On the other hand, noticeable differences between decomposition rates of different species under the same climatic conditions indicated that other factors, connected with substrate composition and/ or soil characteristics, must also play an important role. One of the first attempts at pinpointing the most important rate-regulating factors, was the classic work by Meentemeyer (1978) who formulated an empirical model relating annual litter mass loss $W(\%)$ to $A E T(\mathrm{~mm})$ and lignin concentration $L$ (\% dry mass) (Fig. 1A):

$W=-1.31369+0.0535 A E T+0.18472 \frac{A E T}{L}(1)$

Using a stepwise regression analysis with $A E T$, $L$, and $A E T: L$ ratio as independent variables, Meentemeyer (1978) found that AET alone accounted for $51 \%$ of the variance in decomposition rates, AET: $L$ ratio added $19 \%$, and $L$ added a negligible $2 \%$. Based on the data used in the analysis, Meentemeyer concluded that AET is by far ("several orders of magnitude") more important as a predictor of leaf litter decomposition rate than is litter quality. In a later work, using a more extensive data set, Meentemeyer (1984) found slightly different models for annual litter mass loss $W$ and decomposition constant $k^{1}$, but still with $A E T$ and $L$ as the sole drivers (Fig. 1B):

$$
\begin{aligned}
W= & (-3.44618+0.10015 A E T)- \\
& -(0.01341+0.00147 A E T) \cdot L \\
k= & (-0.5365+0.00241 A E T)- \\
& -(-0.01586+0.000056 A E T) \cdot L
\end{aligned}
$$

Meetemeyer (1984) noted, however, that the lignin control over decay rate varies with the climate, and in wet tropics (high AET) small differences in initial lignin concentration can produce large differences in litter decomposition rates. Nevertheless, at least some independent data for temperate forests show a reasonably good predictive value of the Meentemeyer (1984) models. For example, Dziadowiec (1987) evaluated decomposition rates of leaf litter originating from five tree species (hornbeam, linden, oak, pine, and spruce), growing in the very same geographical area; the Białowieża National Park, Poland, and still exhibiting large differences in decay rates. The decomposition rate constant $k$ for the fastest-degrading hornbeam was -1.06 , and only -0.21 for the slowest-decomposing Scots pine, resulting in $t_{95}$ (time needed to decompose 95\% organic matter): 2.83 years for hornbeam, and 14.29 years for the pine. Dziadowiec (1987) concluded that the initial decomposition rate was determined by morphological and chemical characteristics of the litters.

${ }^{1}$ The decomposition constant $k$ is derived from the exponential decomposition model $\mathrm{dW} / \mathrm{dt}=\mathrm{W}_{0} \exp (\mathrm{kt})$, where $\mathrm{W}$ stands for litter weight, $\mathrm{t}$ is time in years, and $\mathrm{W}_{0}$ the initial weight of the decomposing litter. 
As the most important characteristics, she indicated C:N ratio and contents of easily soluble chemical compounds. Meentemeyer's (1984) model with $A E T=650 \mathrm{~mm}$ (approximate value for that part of Poland), gives a good prediction of the measured minimum and maximum $k$ values when extreme known lignin concentrations are used: $k=-0.21$ for $L=40 \%$ dry mass, and $k=-0.97$ for $L=3 \%$. Unfortunately, lignin concentration was not measured in that study so it is hard to treat these results as the real model validation. The data did show, that at least under certain circumstances, the relatively simple models allow for a reasonably good prediction of the decomposition rates.

More recently, Kurz-Besson et al. (2006) did studies on the decomposition of pine needle litter along a latitudinal climatic gradient spanning from $40^{\circ}$ to $60^{\circ} \mathrm{N}$ (AET ranging from 397 to $629 \mathrm{~mm}$ ). They found, in turn, that not AET but a bit more complicated climate measure - the combined response function (CRF), gave a better explanation of the decay rate. The CRF combines information on the response of litter decomposition to changing temperature $\left(Q_{10}\right)$ with the moisture response function, based on annual water deficit (DEF) and $D E F$ threshold at which the response function reaches its minimum $\left(D E F_{\text {lim }}\right)$ :

$$
C R F=Q_{10}^{\left(T_{1}-T_{2}\right) / 10} \frac{D E F_{\lim }-D E F}{D E F_{\lim }}
$$

where:

$T_{1}<T_{2}$

The first year's mass loss of litter originating from three pine species (Pinus sylvestris, P. pinaster and $P$. halpensis) was found to correlate with AET at $r=0.456$, while CRF gave the correlation coefficient $r=0.940$. This meant that as much as $88 \%$ of the variance in litter decomposition rate in the first year, could be explained by this relation. It is important to remembered, that the authors used substrate of very limited variability, representing only three species from one genera.

The examples provided above show that even simple functions relating litter decomposition rate to climatic factors, and possibly one characteristic of the litter chemistry (e.g., lignin), can provide a satisfactory explanation. Doubts do exist about the universality of the models. Some discrepancies that have been noted for ecosystems outside the temperate climatic zone, and examples of studies pointing out large proportions of unexplained variance even within the areas for which the models have been developed, are presented below.

\section{The doubts}

Despite the information above, some data on leaf litter decomposition within similar climatic conditions seem to undermine such simple models. In a review of published litter decomposition studies from North American temperate forests, Cameron and Spencer (1989) reported decomposition rate constants $k$ covering a very broad range from -0.08 (beech leaves) to -5.23 (Chinese tallow). This translates to the difference in $t_{95}$ of 37.4 vs. 0.57 years, respectively. In their own studies, Cameron and Spencer (1989) compared the decay of the native Texas black willow litter with the introduced Chinese tallow tree litter. Despite identical incubation conditions, the Chinese tallow leaves decomposed much faster than the willow leaves: the $k$ values were -4.33 and -0.35 , and the estimated $t_{95} 0.7$ and 8.6 years, respectively. They concluded that the faster decomposition of tallow leaves was mostly due to a lower lignin concentration. It is questionable whether the approximately twofold difference in lignin concentration (10.5\% in Chinese tallow leaves vs. 23.7\% in willow leaves) was responsible for such a large difference in decomposition rates. The authors themselves noted, that the decomposition rates calculated from the model by Meentemeyer (1978) resulted in $k=-1.39$ for Chinese tallow tree litter, which is much lower than the actual measured value. On the other hand, black willow leaves decomposed substantially slower than predicted by the model (calculated $k=-0.88$ ). This discrepancy between observations and the prediction, using Meentemeyer's (1978) model, brought Cameron and Spencer (1989) to the conclusion that in these particular conditions other factors than just climate and leaf lignin concentration must determine litter decomposition. They suggested that concentration of some secondary plant products, such as tannins and phenols in leaf litter, may be an important rate-regulating factor due to their inhibitory effect on detritus feeders. This still does not explain the exceptionally fast decomposition of tallow tree litter.

Similarly, Blair and Crossley (1988) found substantial inter-species variability in litter decomposition rates within identical climatic conditions: 
among three studied species, flowering dogwood exhibited the fastest decomposition rates with $k=-0.71$ to -1.35 , depending on the study site, red maple exhibited intermediate rates $(k=-0.48$ to -0.84$)$, and chestnut oak the slowest rates $(k=-0.29$ to -0.66$)$. Comparing the chemistry of the litter fall originating from the three species, Blair (1988) concluded that the observed differences in decomposition rates during the first two years of decay can be explained by substrate quality and the resulting interactions with the decomposer community. He also pointed out the fact, that different factors can prevail in different stages of the decay. Thus, in the first six months of decomposition, the content of water-soluble compounds was the most important rate-regulating factor, while lignin became more significant later.

One way to find out the substrate related, decay-determining factors is by incubating litters which range in their chemical composition, at the very same climatic and soil conditions. Following that approach, Berg and Lundmark (1987) studied decomposition of leaf litter originating from two pine species: Scots pine and lodgepole pine. They related the mass loss rate to their chemical characteristics. When combining both species, they found the decomposition rate to be positively related to concentrations of water soluble compounds and nitrogen concentration, while lignin had a negative affect. The decay rate was also related to phosphorus concentration, but only at the single species level. In the early decomposition stage, phosphorus appeared the most important rate-regulating factor in lodgepole pine. When combining phosphorus and water-soluble concentrations, Berg and Lundmark (1987) were able to explain as much as $95 \%$ variance in the early stage decomposition rate of lodgepole pine. Even better results were obtained for Scots pine with phosphorus and nitrogen concentrations as the decay-driving factors. Such a model explained 99\% of the mass loss rate. On the other hand, lignin concentration explained $80 \%$ of the latestage mass loss in Scots pine litter, but for lodgepole pine, only ca. $30 \%$ of the variance in decay rate could be ascribed to lignin. This brought Berg and Lundmark (1987) to the conclusion that apparently some other factor was more important in the latter case which their study must have missed.

Thus, although $A E T$ is one of the most important decay-regulating factors over large climatic scales, the large variability of decomposition rates under similar AET conditions apparently needs an explanation. One attempt at an explanation was the work by Breymeyer and Laskowski (1999), who analyzed decomposition data for Scots pine needles along the $1,500 \mathrm{~km}$ long transect extending from Belarus to Germany. In contrast to other transect studies, which usually cover a broad range of $A E T$ values, this transect was traced longitudinally, with only minor $A E T$ variability but with strong emphasis on the gradient between continental and oceanic climates. Thus, the most important factors differentiating eastern and western ends of the transect were annual temperature amplitude (TAMP), average temperatures in the coldest (TJAN) and warmest (TJUL) months, and annual amplitude in precipitation (PAMP) rather than AET. Using a series of statistical analyses, they estimated that even within very similar AET conditions, climatic factors explained approximately $36 \%$ of the variability in decomposition rates, while $21 \%$ could be ascribed to soil $\mathrm{pH}$ and $\mathrm{N}$ status. Over $40 \%$ of the variance remained unexplained despite using very uniform leaf litter originating from just one species.

Looking for other possible factors which might explain that part of the variance in litter decomposition rates that cannot be determined by climatic factors, and concentrations of lignin, soluble compounds, $\mathrm{N}$ or soil pH, Breymeyer et al. (1997) included in their analysis, a range of metals. They found the surprisingly high correlations between the decay rate of pine needles and litter concentrations of nickel $(r=-0.89)$, iron $(r=0.83)$, zinc $(r=-0.80)$, and lead ( $r=0.82)$. Unfortunately, it is hard to judge the meaning of these correlations as the authors did not provide any more in-depth statistical analysis, such as partial correlations or stepwise regression, which would allow for excluding highly inter-correlated variables. From the results provided, it seems clear that only a few of these correlations, if any, can be really meaningful as many of the studied elements are highly correlated with each other.

An interesting approach was taken by Gallardo and Merino (1993). In addition to the commonly studied chemical litter characteristics, they used a measure of leaf resistance to mechanical damage called leaf "toughness" (TG) assessed as a power necessary to puncture a leaf; for details see Gallardo and Merino (1993). For a range of litter types, with $k$ values ranging from -0.34 to -1.07 at one site (La Sauceda, Spain) and from 
-0.14 to -0.34 at another (La Doñana, Spain), they found that either the toughness alone (La Sauceda) or in combination with nitrogen (TG: $N$ ratio; $L a$ Doñana) gave very high correlations $(r)$ with the 2-year litter mass loss (ML): -0.93 and -0.85 , respectively, for the following power functions:

$$
\begin{aligned}
& \text { La Sauceda: } M L=562 \cdot T G^{-0.34} \\
& \text { La Doñana: } M L=545 \cdot(T G / N)^{-0.38}
\end{aligned}
$$

Altough it is not clear what the measured "toughness" exactly means from biological point of view, it may be argued that it combines leaf characteristics responsible for its resistance to both microbial degradation (lignin concentration) and faunal grazing (cuticle). As such, it can serve as an even better predictor of leaf litter decomposition rate then lignin concentration alone, especially in early decay stages. The study can also support the supposition by Blair (1988) about the importance of interactions between substrate quality and the decomposer community. It is worth mentioning, that in contrast to a number of other papers reporting simple correlations with a range of chemical litter characteristics, Gallardo and Merino (1993) based their conclusions on a stepwise regression, selecting from 17 different characteristics: holocellulose, lignin $(L)$, cutin, tannins, soluble carbohydrates, crude fat, N, P, TG, C:N, C:P, L:N, L:P, cutin:N, cutin:P, TG:N, TG:P. Correlation between the decomposition rate and the lignin concentration was not significant at either site.

The importance of species-specific litter characteristics for the rate of litter decomposition was recently stressed by Cornwell et al. (2008) in an extensive review of decay data for 818 species. Among the 66 studies performed on six continents, the authors found 14 experiments in which the decomposition of litter from more than 20 species was followed in the same climatic zone, thus excluding any climate effects. Over an 18-fold range in decomposition rates was found in these studies. This was a substantially larger range than that found for one species across broad climatic gradients. However, the authors were not able to identify clearly specific litter characteristics responsible for that broad rage of decomposition rates. Instead, they suggested that more complex functional characteristics, that they called 'leaf economic traits', rather than single chemical components, affected the decomposition rates (for more explanation of the term, see the original article by Cornwell et al. 2008).

\section{How about the tropics?}

Despite of the perturbing destruction of tropical rainforests, they still occupy a vast area of approximately $8.3 \times 10^{6} \mathrm{~km}^{2}$ (Whitmore 1998). This is over $20 \%$ of the earth's forested area $\left(>40 \times 10^{6} \mathrm{~km}^{2}\right)$. However, leaf litter decomposition in the tropics has been rarely studied in comparison to middle latitudes. Although some data exist, they have been collected in randomly located studies, not really exploiting the huge potential of incomparable tree species diversity, characteristic to tropical rainforests. Middle- and high-latitude forests consist of just a few tree species, reaching possibly a dozen species per ha. The world record is 307 species per ha in the Ecuadorian Amazon (Whitmore 1998). This provides a huge potential, which has not been exploited so far, for studying the factors determining the decomposition rate.

In recent years, a number of papers have been published with the aim of finding some general global patterns in litter chemistry (e.g., Liu et al. 2006; Kang et al. 2010) and litter decomposition (e.g., Kang et al. 2009). However, due to the scarcity of data, only very few studies from tropical forests and almost none from montane cloud forests are included in such analyses. The huge asymmetry in data availability between boreal and temperate forests on the one hand, and tropical ones on the other, makes such studies prone to potentially heavy bias. For this reason, studies on litter chemistry and organic matter decomposition in tropical forests may have a large impact on our understanding of factors determining litter decay on a global scale.

As it is commonly accepted that primary productivity of tropical rainforests is nutrient limited, Hobbie and Vitousek (2000) tested the hypothesis that the leaf litter decomposition rate is also limited by low availability of $\mathrm{N}$ and $\mathrm{P}$. They applied mineral fertilization of experimental plots in Hawaii and transplanted the litter bags reciprocally between the plots of different treatments. The effect of fertilizations ( $N$, $P$, or $N$ and $P$ combined) was assessed by comparing the treatments against the control litter and the control plot using analysis of variance. The authors concluded that $\mathrm{N}$ addition had no effect on the decomposition rate, even in places where primary productivity was 
clearly $\mathrm{N}$-limited. On the other hand, at the older stand, where $P$ limits the productivity, fertilization with $\mathrm{P}$ and $\mathrm{N}+\mathrm{P}$ increased the decomposition rate. Consequently, they concluded that in tropical rainforests nutrients may limit decomposition in low-P rather than in low- $\mathrm{N}$ ecosystems. A re-analysis of the data from Hobbie and Vitousek (2000) with correlation and multiple regression analysis, gave a somewhat different picture (cf. Fig. 2). The reanalysis was possible thanks to the reporting of detailed data on litter chemistry in the article. The authors measured the contents of: N, P, Ca, Mg, $\mathrm{K}$, lignin, ash, nonpolar extractives, water solubles, acid solubles, acid insolubles, tannins, water soluble glucose equivalents and acid soluble glucose equivalents. The simple correlation analysis gave significant correlations of the decay rate (measured as percent of organic matter decomposed after two years; $\mathrm{OM}_{\mathrm{dec}}$ ) with concentrations of the following chemicals: $\mathrm{N}(r=0.94), \mathrm{Mg}(r=0.66)$, $\mathrm{K}(r=0.61)$, and nonpolar extractives $(r=-0.87)$. However, a number of independent variables were highly inter-correlated, which required removing them before running multiple regression analysis. Also, the decomposition data were available for 12 cases altogether, representing three different study sites and four treatments (the control, $\mathrm{N}, \mathrm{P}, \mathrm{N}+\mathrm{P})$. This meant that the number of independent variables had to be reduced to less than the number of cases, in order to make any further analysis possible. Finally, the following original variables by Hobbie and $\mathrm{Vi}$ tousek (2000) were used in regression analysis: $\mathrm{N}, \mathrm{P}, \mathrm{Ca}$, $\mathrm{Mg}, \mathrm{K}$, lignin (L), nonpolar extractives (NPE), water solubles (WS), and acid solubles $(A S)$. The forward stepwise selection procedure ( $p$-to enter 0.05), usually allowing extraction of the simplest possible model with sufficient predictive power, did result in a simple relationship with just $\mathrm{N}$ concentration as the only significant variable:

$$
\mathrm{OM}_{\mathrm{dec}}=26.25+6.407 \mathrm{~N}
$$

The model is significant at $p<0.0001$ and explains over $87 \%$ of the variance in decomposition rates. It is important to note, that such a simplistic model, although highly significant and theoretically able to explain part of the variance in decomposition rates, is almost totally driven by the differences between the study sites - all points with high $\mathrm{N}$ concentration originate from one site (Fig. 2).

In another $\mathrm{N}$ and $\mathrm{P}$ fertilization experiment in a Costa Rican tropical forest, Cleveland and Reed (2006) found no nutrient fertilization effect on leaf litter mass-loss rates. They also noted that in those forests, the disappearance of dead organic matter was dominated by leaching of dissolved organic matter by heavy rainfalls rather than direct mineralization connected with $\mathrm{CO}_{2}$ evolution. This would mean that in such tropical ecosystems, the actual microbial decomposition is shifted from the litter layer to the soil, where dissolved organic matter leached from leaf litter is mineralized (Cleveland \& Reed, 2006). If this is the case, then the chemical

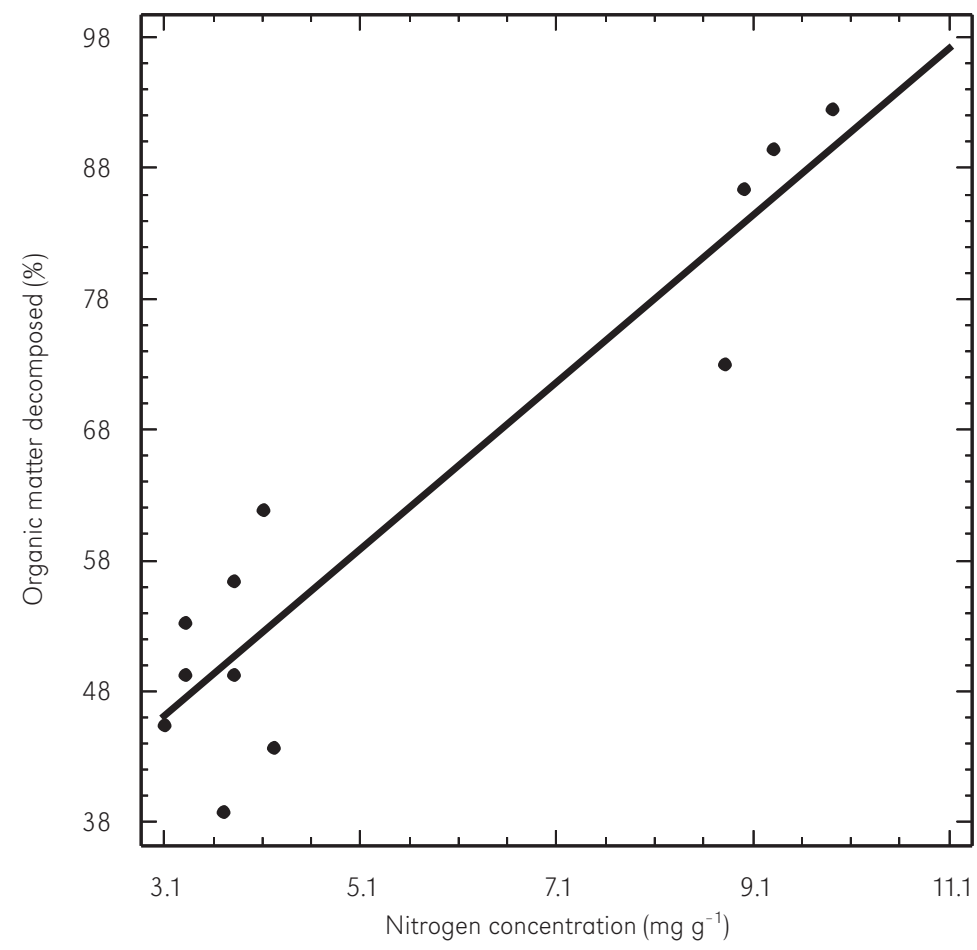

Figure 2. Relationship between the organic matter decomposition rate (\% decomposed in two years) and the nitrogen concentration in litter - regression based on data from Hobbie and Vitousek (2000). Note that the relationship is driven mostly by the four litters with exceptionally high $\mathrm{N}$ concentrations originating from the same study site. 
conditions in the soil rather than the litter chemistry itself, would be the main drivers of the mineralization rate. This would make decomposition models based on data originating from temperate and boreal forests inadequate to wet tropical ecosystems. Indeed, in a study on decomposition of standardized organic matter along an altitudinal transect in Andes (65 - 3968 m a.s.l.) in Venezuela, Couteaux et al. (2002) found that although the decay rate was determined mostly by climate, the decomposition rates corrected for climate effect still differed significantly between the study sites. As the degrading material was identical at all sites, they concluded that factors linked to soil properties must have been responsible for these residual differences.

\section{What next?}

In conclusion, the relatively simple empirical equations already formulated some three decades ago by Meentemeyer $(1978,1984)$, are probably still the most universal decomposition models allowing for a reasonably good prediction of leaf litter decomposition rates in temperate forests. The models, though, fail in more extreme climates. In his 1984 work, Meentemeyer already noticed that the relationship did not work properly for Norwegian forests (the correlation between the lignin concentration and the decomposition rate of different litters incubated at the very same site was only -0.333 and was nonsignificant at $p=0.05$ ). Gallardo and Merino (1993) found, in turn, that in areas with a typical Mediterranean-type climate, the two-year decay rate did not correlate with lignin concentration alone, and only in one of the two study areas was there a significant correlation with L: $\mathrm{N}$ ratio. In both cases, leaf toughness used either alone or in combinations with $\mathrm{N}$ and $\mathrm{P}$, did give high and significant correlations ( $r$ up to -0.93). In wet tropical forests the relationships are probably even more complex. The relatively few existing studies indicate the crucial role of leaching of dissolved organic matter from litter and its mineralization in soil. Hence, soil conditions seem as important for the decomposition rate as the litter chemistry itself.

It seems that one problem with the search for the ultimate decomposition model, is the scarcity of properly designed, large scale studies, with a broad range of chemical analyses of both litter fall and the soil in which the decomposition proceeds. On top of that comes the rather poor data analysis in many articles, which does not exploit properly even that limited available information. One of the common problems with data analysis stems from the high inter-correlation between many litter and soil chemical characteristics. These correlations make it difficult to sort out the factors most important to the decomposition rate from those factors of minor effect but correlated with the decisive ones. Unfortunately, the only way to overcome this difficulty is to analyze immense data sets, representing a broad range of climatic conditions, soil types, and litter characteristics.

I believe that the next steps towards formulating more precise and elaborate global-scale decomposition models should be the following: (1) building an extensive data base containing as many decomposition studies as possible, covering forests of all climatic zones and a comprehensive set of climatic and chemical information; (2) running proper statistical analysis on available data and formulating models; (3) identifying gaps in available information (i.e. potentially important chemical properties of litter which are not represented well enough in the data base); and (4) arranging international collaborative research project(s) aiming strictly at filling the gaps. Although not necessarily very cheap (the cost will depend on the extent of the gaps identified in the data), this would be the most effective way towards formulating a satisfactory leaf litter decomposition model. Gallardo and Merino (1993) indicate that litter decomposition studies should also include some information about the palatability of leaf litter for litter-feeders and on the abundance of litter-feeders in the soil-litter subsystem. Although animals do not decompose dead plant material directly, their influence on decomposition can be substantial in many ecosystems. A healthy cooperation between specialists in organic matter decomposition, soil microbiologists, and zoologists is indispensable.

\section{Acknowledgements}

I wish to thank Alicja Braymeyer for her invaluable input into the studies on litter decomposition, and specifically for her help and guidance in my own work on the subject. Comments by anonymous referees are appreciated.

Editors' note:

Unless otherwise stated, the sources of tables and figures are the author(s), on the basis of their own research. 


\section{References}

Berg B., Lundmark J.E., 1987. Decomposition of needle litter in Pinus contorta and Pinus sylvestris monocultures - a comparison. Scandinavian Journal of Forest Research, vol. 2, iss. 1-4, pp. 3-12

BLAIR J.M., 1988. Nitrogen, sulfur and phosphorus dynamics in decomposing deciduous leaf litter in the southern Appalachians. Soil Biology and Biochemistry, vol. 20, no. 5, pp. 693-701.

BlaiR J.M., Crossley D.A. JR., 1988. Litter decomposition, nitrogen dynamics and litter microarthropods in a southern Appalachian hardwood forest 8 years following clearcutting. Journal of Applied Ecology, vol. 25, no. 2, pp. 683-698.

Breymeyer A., Degorski M., Reed D., 1997. Decomposition of pine-litter organic matter and chemical properties of upper soil layers: transect studies. Environmental Pollution, vol. 98, iss. 3, pp. 361-367.

BreYMeYer A., LASKOWSKI R., 1999. Ecosystem process studies along a climatic transect at $52-53^{\circ} \mathrm{N}(12-$ $32^{\circ}$ E): pine litter decomposition. Geographia Polonica, vol. 72, no. 2, Papers in Global Change IGBP, no. 6, pp. 45-64.

Cameron G.N., Spencer S.R., 1989. Rapid leaf decay and nutrient release in a Chinese tallow forest. Oecologia, vol. 80 , iss. 2, pp. 222-228.

Cleveland C.C., Reed S.C., Townsend A.R., 2006. Nutrient regulation of organic matter decomposition in a tropical rain forest. Ecology, vol. 87, iss. 2, pp. 492503.

Cornwell W.K., Cornelissen J.H.C., Amatangelo K., Dorrepaal E., Eviner V.T., Godoy O., Hobbie S.E., Hoorens B., Kurokawa H., Pérez-Harguindeguy N., Quested H.M., Santiago L.S., Wardle D.A., Wright I.J., Aerts R., Allison S.D., van Bodegom P., Brovkin V., Chatain A., Callaghan T.V., Diaz S., Garnier E., Gurvich D.E., Kazakou E., Klein J.A., Read J., Reich P.B., Soudzilovskaia N.A., Valeretti M.V., Westoby M., 2008. Plant species traits are the predominant control on litter decomposition rates within biomes worldwide. Ecology Letters, vol. 11, iss. 10, pp. 1065-1071.

Coûteaux M.M., Sarmiento L., Bottner P., Acevedo D., THIÉRY J.M., 2002. Decomposition of standard plant material along an altitudinal transect $(65-3968 \mathrm{~m})$ in the tropical Andes. Soil Biology and Biochemistry, vol. 34 , iss. 1, pp. 69-78.

DZIADOWIEC H., 1987. The decomposition of plant litter fall in an oak-linden-hornbeam forest and an oakpine mixed forest of the Białowieża National Park. Acta Societatis Botanicorum Poloniae, vol. 56, no. 1, pp. 169-185.

Gallardo A., Merino J., 1993. Leaf decomposition in two Mediterranean ecosystems of southwest Spain: influence of substrate quality. Ecology, vol. 74, no. 1, pp. 152-161.

HobBie S.E., Vitousek P.M., 2000. Nutrient limitation of decomposition in Hawaiian forests. Ecology, vol. 81, iss. 7, pp. 1867-1877.

Kang H., Berg B., Liv C., Westman C.J., 2009. Variation in mass-loss rate of foliar litter in relation to climate and litter quality in Eurasian forests: differences among functional groups of litter. Silva Fennica, vol. 43, iss. 4, pp. 549-575.

Kang H., Xin Z., Berg B., Burgess P.J., LiU Q., LiU Z., LI Z., LIU C., 2010. Global pattern of leaf litter nitrogen and phosphorus in woody plants. Annals of Forest Science, vol. 67, iss. 8, p. 811.

Kurz-Besson C., Coûteaux M.M., Berg B., Remacle J., Ribeiro C., Romanyà J., Thiéry J.M., 2006. A climate response function explaining most of the variation of the forest floor needle mass and the needle decomposition in pine forests across Europe. Plant and Soil, vol. 285, pp. 97-114.

liu C., Berg B., Kutsch W., Westman C.J., Ilvesniemi H., Shen X., Shen G., Chen X., 2006. Leaf litter nitrogen concentration as related to climatic factors in Eurasian forests. Global Ecology and Biogeography, vol. 15 , iss. 5, pp. 438-444.

MeentemeYer V., 1978. Macroclimate and lignin control of litter decomposition rates. Ecology, vol. 59, iss. 3, pp. 465-472.

Meentemeyer V., 1984. The geography of organic decomposition rates. Annals of the Association of American Geographers, vol. 74, no. 4, pp. 551-560.

WhitMORE T.C., 1998. An introduction to tropical rain forests. Oxford: Oxford University Press, 296 pp.
(C) Ryszard Laskowski

(C) Geographia Polonica

(C) Institute of Geography and Spatial Organization,

Polish Academy of Sciences, Warsaw, 2012
Article first received • January 2012 Article accepted $\bullet$ June 2012 